Impact Factor $7.105 \div$ Vol. 9, Issue 1, January 2022

DOI: 10.17148/IARJSET.2022.9101

\title{
Geothermal Energy Potential of Egypt - Review Paper
}

\author{
Walid Tarek Kortam¹, Ayman Abbas ${ }^{2}$, Ahmed A.A. Attia ${ }^{3}$ \\ Engineer, Renewable Energy Engineering, British University in Egypt, Cairo, Egypt ${ }^{1}$ \\ Professor, Mechanical Engineering Department, British University in Egypt, Cairo, Egypt ${ }^{2}$ \\ Combustion and Energy Technology Lab, Shoubra Faculty of Engineering, Benha University, Cairo, Egypt ${ }^{3}$
}

\begin{abstract}
With global concerns over climate change due to fossil fuel emissions, and global initiatives to limit the adverse effects fossil fuel emissions at the current rate will potentially cause, Egypt along with the other countries have a role in limiting their fossil fuel emissions. Egypt's "vision 2030" targets tackling the emissions by including solar, wind and hydro resources as clean sources for electricity production.

Studies show that Egypt has potential geothermal resources that could be utilized in direct heating applications and even for small scale electricity production. These resources have yet to be exploited but could potentially aid Egypt in meeting its future energy demands in a "cleaner" way. This paper reviews the available literature related to geothermal potential studies of Egypt.
\end{abstract}

Keywords: renewable energy, Egypt's geothermal potential, fossil fuel emissions, climate change

\section{INTRODUCTION}

Geothermal energy is energy made available by the exploitation of the naturally occurring heat beneath the Earth's surface. This energy is the result of the decay of radioactive minerals found beneath the crust of the Earth [1]. This energy is usually exploitable with the use of water/steam as a carrier of the heat from the subsurface to the surface.

It is reported that geothermal exploitation first began thousands of years ago for direct heating applications, such as cooking and bathing [2]. Industrial application of geothermal is reported to be in the $19^{\text {th }}$ century for the chemical process of boric acid extraction. In Larderello, Italy, in 1904 the first geothermal power plant was run for the production of electricity. The plant powered a number of lightbulbs. The plant upgraded its power capacity to 5 MW by the year 1915 . In 1958, the second geothermal plant was established in New Zealand. The plant currently generates an annual energy of 1,550 GWh. Geothermal energy exploitation has since been adopted by several countries, with America, Indonesia and the Philippines being the largest producers of geothermal energy around the world. The global geothermal power capacity was estimated to be 15,608 MWe in 2020 [3]. Geothermal energy exploitation technologies have matured and showed their advantages which include limited emissions and environmental impact and reliability.

The heat produced from the underground can be utilized directly for heating purposes. This can range from residential space heating to industrial heating processes. The heat can also be utilized in electricity generation by producing steam that rotates a turbine connected to a generator.

Egypt depends on fossil fuels to meet its energy demands, with $91 \%$ of its electricity demand and $94 \%$ of its fuel consumption supplied by fossil fuels [4]. Having shown to have potential geothermal energy resources [5], Egypt can start making use of these resources that have yet to be exploited. The studies conducted have shown that potential resources exist in the Eastern desert, but the highest potential resources are in the Western desert, around the Gulf of Suez area. With the Gulf of Suez area already being exploited for its hydrocarbon resources, with many wells already drilled, repurposing some of the abandoned wells for geothermal exploitation could even increase the economic feasibility of geothermal energy projects in the area [6]. With a growing energy demand coupled with the need to limit fossil fuel emissions, Egypt can begin to explore the potential of these resources.

\section{LITERATURE REVIEW}

Geothermal resources are identified as having the following components: permeable rock as a conduit, fluid as a medium or carrier and heat which is the target for exploitation. The best geothermal resources are typically the resources that already have these components existing naturally. It is important to note that geothermal energy is considered as a renewable energy since the energy is constantly being generated beneath the Earth. However, for a successful long term geothermal project to be reliable, the rate of heat extraction should be properly designed to not exceed the regeneration rate of the heat. This way, a reliable and stable energy rate can be exploited for a long period of time [7]. 


\section{International Advanced Research Journal in Science, Engineering and Technology \\ Impact Factor $7.105 \div$ Vol. 9, Issue 1, January 2022 \\ DOI: 10.17148/IARJSET.2022.9101}

There three types of geothermal power plants, namely dry steam, flash and binary cycle power plants. The type of power plant to be used depends heavily on the resource temperature and the fluid state of the resource. Dry steam plants are utilized for resources where the fluid exists downhole and is produced as steam to the surface. The steam is used directly to turn a turbine to generate the required electricity. The condensed water is then reinjected into the reservoir to maintain pressure. This type of resource is the most efficient to exploit but is rarely found. Flash steam plants are used when the fluid occurs downhole as hot water. During production of the hot water, it flashes into steam due to pressure drop. The steam can then be utilized in a similar fashion to dry steam plants. Binary plants are utilized for lower temperature resources typically below $204{ }^{\circ} \mathrm{C}$. With the use of a heat exchanger, the produced hot water exchanges its heat to a fluid that has a lower boiling point than water. This fluid then vaporizes to turn the turbine for electricity generation. The cooled down water is also reinjected to the reservoir [8].

Resources exist that have the key component, heat, naturally but either lack the fluid, permeability or both. Technology advancements have led to the ability of extracting heat from these resources. Resources lacking both components are called hot dry rocks (HDR) and the technology used for extraction is called enhanced geothermal systems (EGS). The technology is basically pumping fluid at a high pressure to induce fractures in the reservoir, thus allowing for the creation of conduits for the fluid medium to flow through. Since the resource is dry with no medium to carry the heat, water is injected from the surface into the fractured reservoir through injection wells, and is produced from after the downhole heat exchange through producer wells. This technology is expected to have a great impact on the advancement of the geothermal energy industry [9].

The following review will focus on the studies done on the geothermal energy potential of Egypt, focusing on identifying the possible type of resources, and possible applications that could fit the Egypt 2030 vision.

Geothermal Potential of Egypt

Egypt has a number of hot springs, which are a basically a surface seepage of heated water from the underground. Figure 1 shows the distribution of these springs, which are distributed around the Gulf of Suez area and the Western desert. The surface temperature of these springs are typically low with the exception of Hammam Faraun spring with $71^{\circ} \mathrm{C}$.

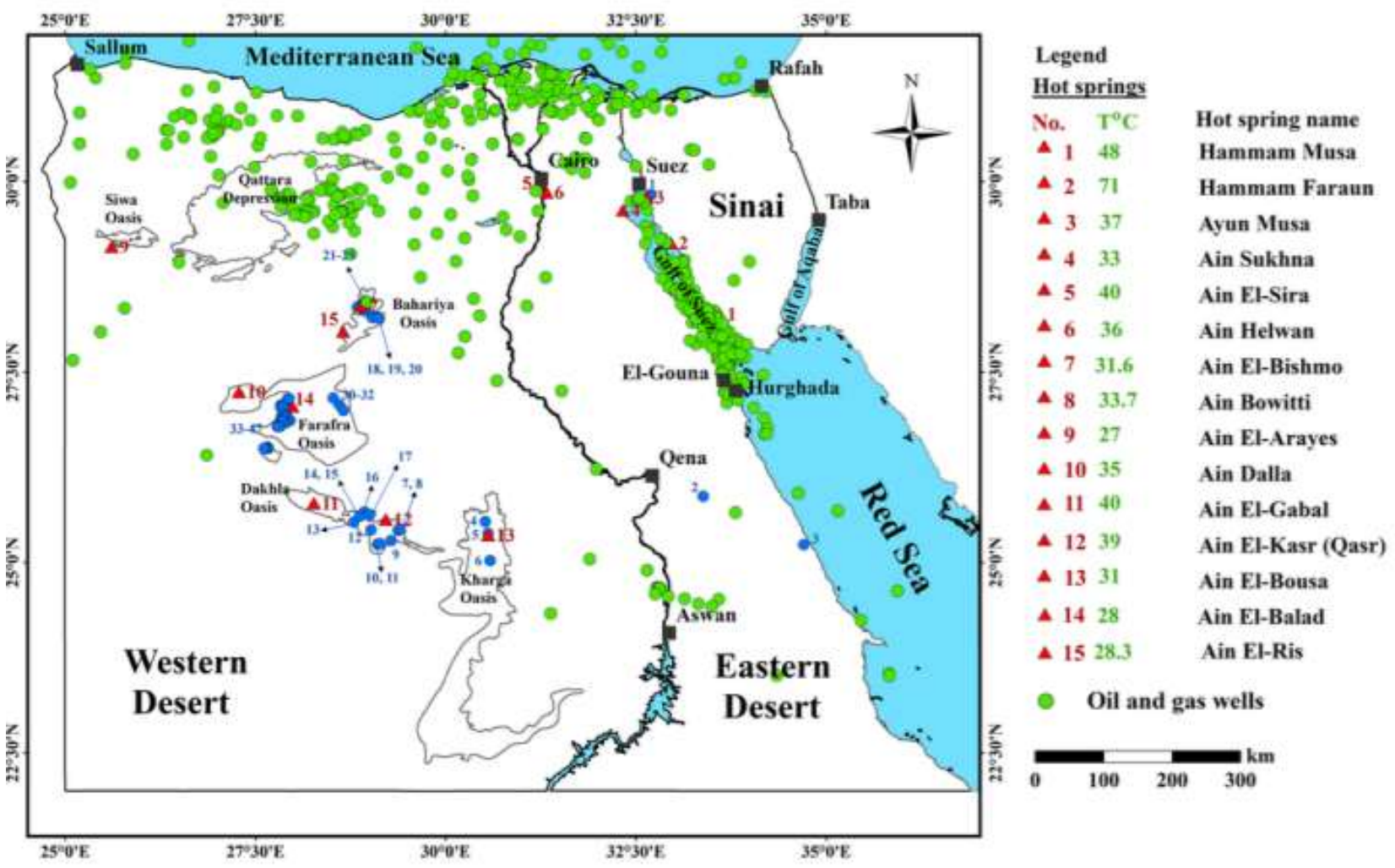

Figure 1 A map showing the hot spring locations in Egypt, represented by red triangles, source [10]

Reported studies related to the potential of geothermal energy in Egypt started in the 1970s. Studies were conducted on several factors focused on collecting and using available data to quantify heat flow values and ultimately a temperature distribution of the geothermal resources in Egypt. [11] Used a chemical analysis approach by analyzing the silica content of produced water from the subsurface from areas all over Egypt. Typical heat flow value is $65 \mathrm{MW} / \mathrm{m}^{2}$ [12]. The findings of the geochemical study was that the Eastern region of Egypt has a higher than normal heat flow value of 75 


\section{International Advanced Research Journal in Science, Engineering and Technology \\ Impact Factor $7.105 \div$ Vol. 9, Issue 1, January 2022 \\ DOI: 10.17148/IARJSET.2022.9101}

$\mathrm{MW} / \mathrm{m}^{2}$, with the highest potential area around the Hammam Faraun spring. The western desert region showed low heat flow values below $50 \mathrm{MW} / \mathrm{m}^{2}$. They concluded that the area around the Hammam Faraun is the highest potential area for future geothermal exploration efforts, and that the area could possibly have a large extension from the Gulf of Suez towards Cairo. According to [13] the resources in the western desert of Egypt can be classified as being low temperature resources. Additionally, the research focused on the Hammam Faraun region, creating a conceptual model of the resource. The model shows that this resource is created from strong underground heat flow, coupled with a string circulation through the faults related to the Gulf of Suez formation.

An integrated approach was conducted by combining available data pertaining to the geological understanding, geophysical data, oil well bottomhole temperature and $\log$ data as well as remote sensor data to create a GIS model. Bottomhole temperature data used for this model was acquired from 596 wells [14]. The aim of the research was to combine all the available data to produce a map of Egypt's geothermal energy distribution. A heat flow map was created Figure 2 showing that the majority of the Egyptian subsurface has normal heat flow values, with come anomalies in the west and south. The map also shows that the Gulf of Suez has high heat flow values near Hammam Faraun and El-Gouna. The highest heat flow values, around $180 \mathrm{MW} / \mathrm{m}^{2}$ are in the Red Sea.

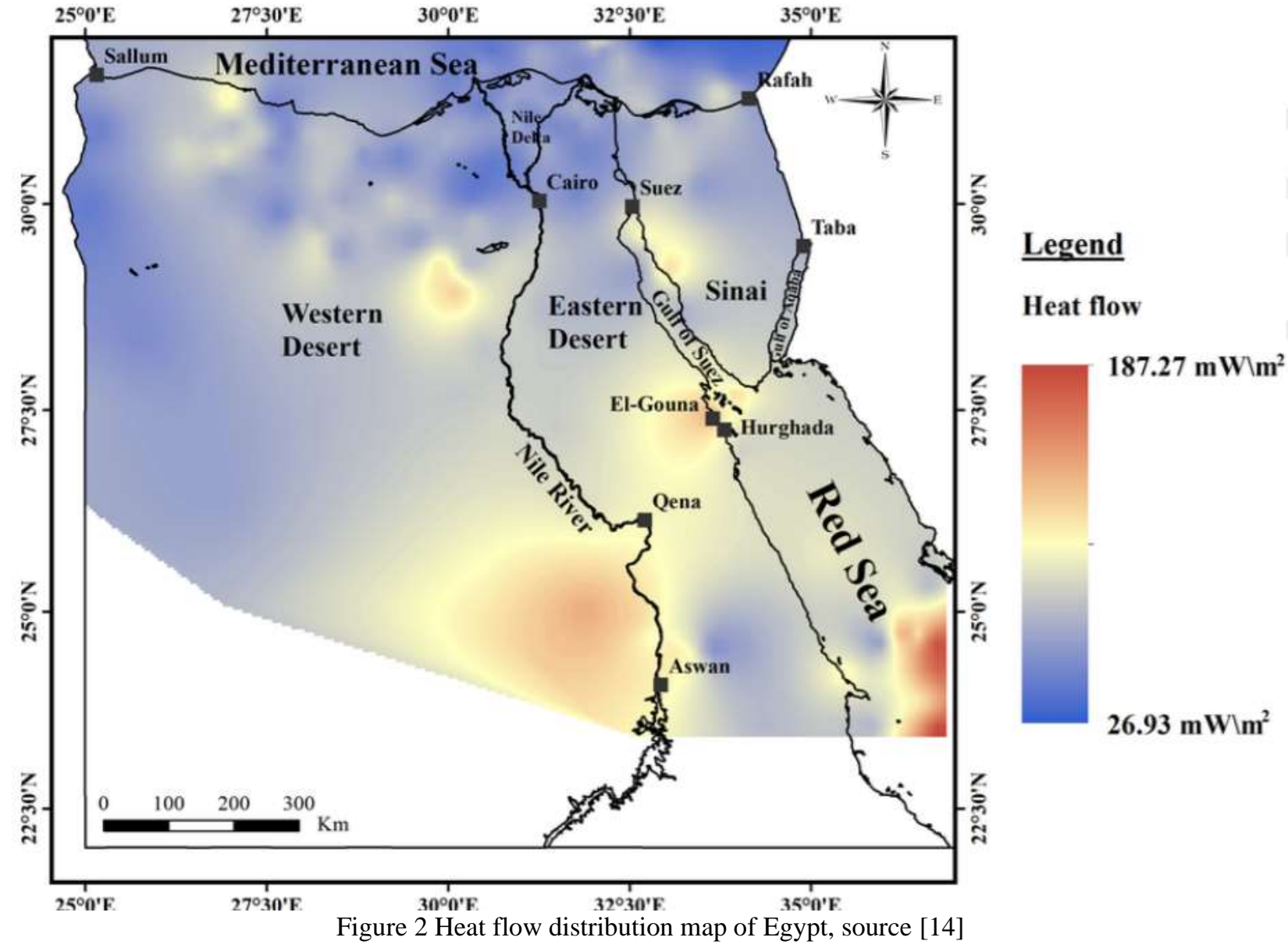

The final potential map created Figure 3 confirms that the highest potential region is in the Eastern Desert, around the Gulf of Suez area and the Red Sea. 


\section{International Advanced Research Journal in Science, Engineering and Technology}

Impact Factor $7.105 \div$ Vol. 9, Issue 1, January 2022

DOI: 10.17148/IARJSET.2022.9101

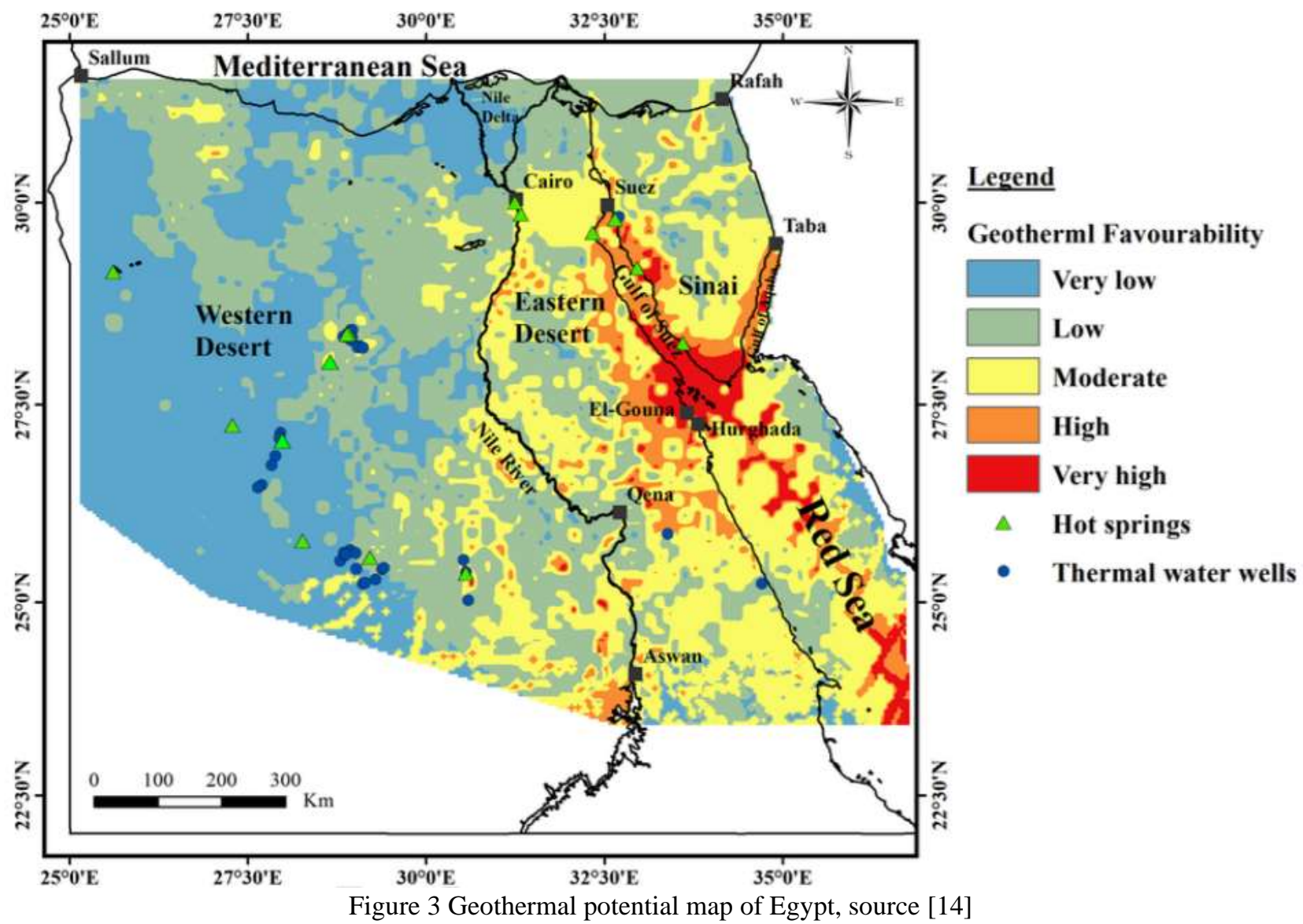

The previous studies focused hydrothermal resources, where water is present as a carrier of heat. A focused research was conducted on hot dry rock potential in the Eastern Desert region, opening up the possibility of the use of EGS systems in the area [15].

The focus of the research was the radiogenic basement granite formation. Calculated heat flow values in the region were up to $220 \mathrm{MW} / \mathrm{m}^{2}$. This has been attributed to the high presence of uranium in the granite.

The resource temperature of the granite at a depth of 2 and $3 \mathrm{~km}$ was then calculated and mapped in Figure 4 . The potential power possible from this resource has not been quantified but adds to the potential geothermal resources in the Eastern Desert of Egypt.

One study investigated resources in the north-western region in detail, by using data from several drilled oil wells. The purpose of the research was to identify possible uses of the geothermal energy in remote locations [16]. The study determined that the low temperature wells around $50{ }^{\circ} \mathrm{C}$ could be utilized for space heating. One well with a producing temperature and high flowrate of production was determined to have an industrial application potential. It was determined that energy from this well can be utilized using a binary power plant, generating enough electricity to pump water to remote areas. investigated the use of geothermal energy to transport fresh water to a remote location. A later study determined that this power plant could produce 100 to $130 \mathrm{~kW}$ of power, with ammonia, having a low boiling point, being the designed secondary fluid [17].

Two studies were conducted to quantify the potential power production of Egypt, specifically the Hammam Faraun resource, using a binary power plant. [18] calculated that 12.4 MWt (thermal Megawatt) of power production for 50 years is achievable while [19] calculated 19.68 MWt for 40 years. 


\section{International Advanced Research Journal in Science, Engineering and Technology}
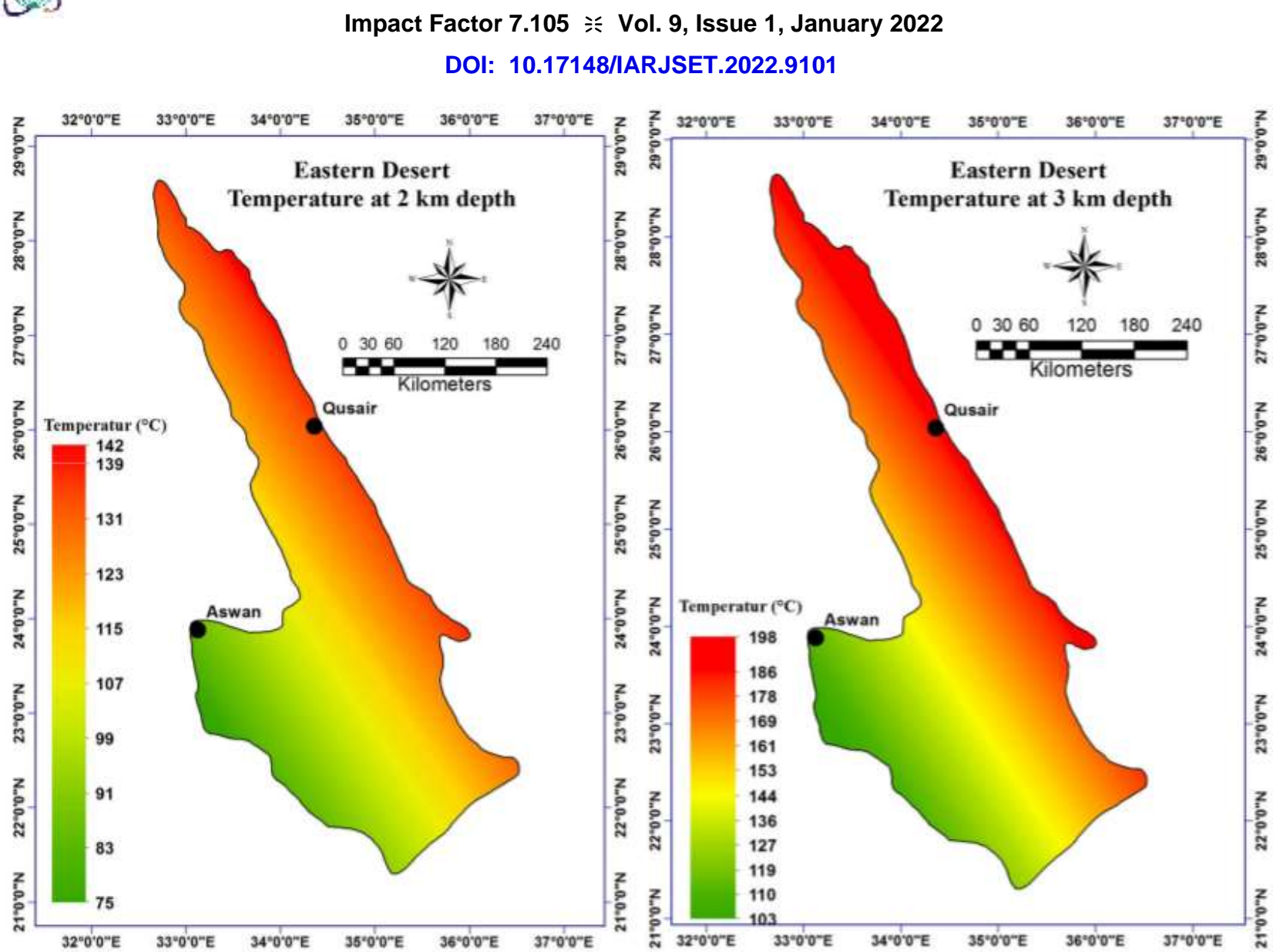

Figure 4 Calculated resource temperature of Eastern Desert granite rock, source [15]

\section{CONCLUSION}

Egypt has yet to tap into its geothermal energy potential. Data gathered from oil and gas wells drilled around Egypt provided sufficient subsurface data that was used in several research studies conducted as far back the 1970s. These studies have concluded that the highest geothermal potential areas are in the Eastern desert around the Gulf of Suez, and in the Red Sea. These resources can be the target for future exploitation for small-scale industrial uses and even electricity production. This can be achieved with the use of binary power plants. Estimated power production of one the highest potential areas, the Hammam Faraun area, ranges from 12.4 to $19.68 \mathrm{MWt}$. One research focusing on hot dry rock in the Eastern Desert has concluded that this region can be exploited using EGS systems. The Western Desert has some low enthalpy resources that can be used for low scale direct uses, such as space heating and irrigation. Exploitation of all these geothermal resources could prove very beneficial to Egypt, in its plans to reduce fossil fuel emissions and add "cleaner" energy production into its energy mix.

\section{REFERENCES}

[1] A. Turgeon and E. Morse, "Geothermal Energy," 20 November 2012. [Online]. Available: https://www.nationalgeographic.org/encyclopedia/geothermal-energy/.

[2] J. W. Lund, "Geothermal Energy," 30 Apr 2018. [Online]. Available: https://www.britannica.com/science/geothermal-energy. [Accessed 22 December 2021].

[3] A. Richter, "ThinkGeoEnergy," 1 Jan 2021. [Online]. Available: https://www.thinkgeoenergy.com/thinkgeoenergys-top-10-geothermal-countries-2020-installed-powergeneration-capacity-mwe/.

[4] L. Abdallah, "Egypt's nationally determined contributions to Paris agreement: review and recommendations," International Journal of Industry and Sustainable Development (IJISD), pp. 49 - 59, 2020. 


\section{International Advanced Research Journal in Science, Engineering and Technology \\ Impact Factor $7.105 \div$ Vol. 9, Issue 1, January 2022 \\ DOI: $10.17148 / I A R J S E T .2022 .9101$}

[5] A. Lashin, "Review of the Geothermal Resources of Egypt: 2015-2020," in Proceedings World Geothermal Congress 2020 , Reykjavik, 2020.

[6] Y. a. L. K. a. L. C. a. M. M. B. Zhu, "Geothermal power production from abandoned oil reservoirs using in situ combustion technology," Geothermal Energy Utilization and Technologies 2020, 2019.

[7] L. Rybach, "Geothermal Sustainability,” in Proceedings European Geothermal Congress, Unterhaching, 2007.

[8] J. W. Lund, "geothermal energy," 30 April 2018. [Online]. Available: https://www.britannica.com/science/geothermal-energy.

[9] D. a. L. A. a. A. N. A. a. A. A. B. Chandrasekharam, "The potential of high heat generating granites as EGS source to generate power and reduce CO2 emissions, western Arabian shield, Saudi Arabia," Journal of African Earth Sciences, 2015.

[10] S. E. H. M. A.-E. E. Mohamed Abdel Zaher, "Geothermal Resources in Egypt integrated with GIS-based analysis," Journal of Volcanology and Geothermal Research, 2018.

[11] C. A. Swanberg, P. Morgan and F. Boulos, "Geothermal Potential of Egypt," Elsevier Science Publishers B.V., Amsterdam, 1983.

[12] J. O'Sullivan, "IRENA," [Online]. Available: https://www.irena.org//media/Files/IRENA/Agency/Events/2014/Jun/2/1_Sullivan.pdf?la=en\&hash=7B8C0F4B0F52944710B21166B FC30352DD7AC288. [Accessed December 2021].

[13] M. Abdelzaher and S. Ehara, "Heat Flow and Geothermal Resources in Egypt," in J. Geotherm. Soc. Japan. Vol. 31, 2009.

[14] M. A. a. E. S. a. E.-S. A. a. M. H. a. E. A. Zaher, "Geothermal resources in Egypt integrated with GIS-based analysis," Journal of Volcanology and Geothermal Research, 2018.

[15] D. Chandrasekharam, A. Lashin, N. A. Arifi, A. A. Bassam, C. Varun and H. K. Singh, "Geothermal energy potential of eastern desert region, Egypt," Environ Earth Sci, 2016.

[16] F. K. Boulos, "GROUNDWATER OF THE AQUIFER SYSTEM OF WESTERN EGYPT- A SOURCE FOR GEOTHERMAL ENERGY,” in 11th New Zealand Geothermal 1989, 1989.

[17] F. K. Boulos, "Use of Geothermal Energy at Kifar Well, Egypt in Water Transportation," in 12th New Zealand Geothermal Workshop, 1990.

[18] A. Lashin, "A preliminary study on the potential of the geothermal resources around the Gulf of Suez, Egypt," Arabian Journal of Geosciences, pp. 2807-2828, 2013.

[19] H. a. A. A. a. L. A. a. R. A. E. Aboulela, "Contribution of geothermal resources to the future of renewable energy in Egypt: A,” Renewable Energy, 2020. 